\title{
Market Transparency, Investor Strategies, and Trading Costs: Evidence from the Taiwan Stock Exchange
}

\author{
Shu-Fan Hsieh (Corresponding author) \\ Department of Money and Banking \\ National Kaohsiung First University of Science and Technology, Taiwan \\ E-mail: shufan@nkfust.edu.tw \\ Hsiu-Kuei Chen \\ Department of Business Administration \\ National Taichung University of Science and Technology, Taiwan \\ E-mail: showguay@ntit.edu.tw
}

Tai Ma

Department of Finance, National Sun Yat-sen University, Taiwan

E-mail: matai@finance.nsysu.edu.tw

Received: March 18, 2012

doi:10.5430/afr.v1n1p180
Accepted: April 25, 2012

Published: May 15, 2012

URL: http://dx.doi.org/10.5430/afr.v1n1p180

\begin{abstract}
This paper investigates the effect of changes in pre-trade transparency on trading strategies and trading costs by examining the effects of increased transparency in the limit order book at the Taiwan Stock Exchange. Our results demonstrate that pre-trade transparency makes the market more liquid, because investors are more willing to provide liquidity, thus reducing the trading costs for liquidity demanders. Furthermore, we find evidence that investors, especially institutional traders, attempt to manage limit-order exposures by splitting orders and cancelling orders faster; thus, pre-trade transparency does not increase their trading costs. Our findings suggest that pre-trade transparency affects trading strategies and trading costs differently according to the type of investor.
\end{abstract}

Keywords: Pre-trade transparency, Execution costs, Order split

\section{Introduction}

Pre-trade transparency is one of the most important issues in security markets. Market transparency refers to the ability of market participants to observe information about the trading process. Although more and more exchanges tend to increase pre-trade transparency, the effect of market transparency, especially on trading costs and strategies, is still an ongoing debate. In January 2003, the Taiwan Stock Exchange increased the limit order book disclosure from the price and depth at the best quote, to those at the top five quotes. This provides a natural experiment of pre-trade transparency to test the impact of transparency enhancement.

There has been considerable debate among academics on the cost and benefits of pre-trade transparency. In general, proponents of pre-trade transparency argue that greater transparency generates lower trading costs for uninformed traders and thus improves liquidity (Pagano and Röell, 1996). Friedman (1993) finds that displaying the entire limit order book reduces the market bid/ask spread and improves liquidity. Gerke et al. (1997) and Chung and Chuwonganant (2009) find lower volatility in the transparent setting (Note 1). Opponents argue that market transparency causes higher price volatility, reduces market liquidity in a thin market, and increases the execution costs after the increase in pre-trade transparency (Madhavan, 1996, and Madhavan et al., 2005). Flood et al. (1999) find increased pre-trade transparency to slow price discovery in a multi-dealer market. Ma et al. (2008) studying pre-trade transparency in Taiwan Stock Exchange, find that liquidity and price efficiency are not improved significantly in transparent markets (Note 2). The 
results of these literatures are not only inconsistent but also focus only on the consequences of changes in pre-trade transparency in terms of market performances. Few studies have traced the effect of pre-trade transparency on trading strategies and trading costs, back to different market participants.

Orders submitted by traders are distinguished into market orders and limit orders (Note 3). Market orders are generally preferred by traders who demand for immediacy, while limit orders are preferred by traders with low demand for immediacy, but concerned with transaction costs. Thus, traders who submit market orders demand for liquidity, while those who submit limit orders provide for liquidity. How does pre-trade transparency affect different traders' strategies and trading costs, which further affect market performances? Baruch (2005) demonstrates that opening the limit-order book is beneficial to liquidity demanders who trade at a lower cost because of the higher transparency. On the other hand, according to Harris (1996), there are two risks faced by liquidity providers: they may reveal private information about the value of the security, and the exposed limit orders can be used to construct trading strategies aimed explicitly at taking advantage of these limit orders. Thus, strategic traders who sense risks may take some actions to mitigate these disadvantages. Boehmer et al. (2005) demonstrates that limit-order traders may attempt to prevent themselves from the limit-order exposure by submitting smaller orders and cancelling orders faster. Distinct from Boehmer et al. (2005), we further classify orders into those submitted from individual and institutional traders. Our findings suggest that only institutional traders trade strategically to avoid risks induced by the limit-order exposure in a more transparent market. Individual traders who trade as liquidity suppliers suffer from the highest trading cost after the pre-trade transparency enhancement.

In this paper, we analyze a complete dataset, which contains all the trading records of all investors on the Taiwan Stock Exchange (TWSE). Our sample covers trading from July 1, 2002 to June 30, 2003, which includes the pre-trade transparency improvement on January 1, 2003. The dataset contains the entire transaction data and the identity of each trader in the Taiwan stock market, which means that our data allows us to identify the trading of individuals and institutions. Our findings suggest that traders are more willing to provide liquidity in the transparent market by submitting more limit orders. Thus, consistent with Baruch (2005), both individual and institutional liquidity demanders, who trade with market orders, benefit from the pre-trade transparency by trading with shorter execution time and lower execution costs. However, liquidity providers, who trade with limit orders, have been compensated less because of their limit-order exposure. Our findings provide evidence that strategic traders, such as institutional traders, attempt to avoid limit-order exposure by canceling orders faster and splitting orders into smaller ones, i.e. they trade more frequently and trade with smaller orders. Individual traders, on the other hand, not only submit more limit orders but also increase the size of orders. Thus, individual liquidity providers suffer loss due to competition. In a word, individual traders provide liquidity at a higher price in a more transparent market while institutional trader strategically split and cancel orders to avoid the risks of a transparent market.

This paper differs from previous work in two aspects. We provide evidence to show the effect of market transparency on different participants by focusing on the change of trading costs. Liquidity demanders benefit most from the disclosure of the limit-order book, while liquidity providers are compensated less in a transparent market. Second, we further examine how liquidity providers change their trading strategies in response to disadvantages. Our findings suggest that institutional liquidity providers, who are more strategic than individuals, will take action to mitigate the loss resulting from a higher pre-trade transparency.

The reminder of the paper is organized as follows. Section 2 describes the market and data. Section 3 introduces the methodology and measures used in this study. Section 4 presents the main empirical results of effects of pre-trade transparency on trading strategies and trading costs. Section 5 concludes the article.

\section{Market and Data Description}

\subsection{Taiwan market rules}

The TWSE operates in a consolidated limit-order book environment in which only limit orders are accepted and executed in strict price and time priority. The regular trading session extends from 9:00 a.m. to 1:30 p.m. Orders can be entered half an hour before the trading session starts. All securities listed on the exchange are traded through Fully Automated Securities Trading (FAST), which is a frequent call auction mechanism. Buy and sell orders are accumulated and cleared every 45 seconds or so at a price that maximizes the trading volume. After each call auction, the highest unexecuted bid price and the lowest unexecuted ask price become the prevailing quotes. In order to maintain a stable stock market, the daily price fluctuation limits for stocks are set at $7 \%$ of the closing price for the preceding trading day. The TWSE charges commissions at $0.1425 \%$ of the value of a trade. Some brokers offer lower commissions for larger traders. Taiwan also imposes a transaction tax on stock sales of $0.3 \%$. Capital gains (both realized and unrealized) are not taxed, while cash dividends are taxed at ordinary income tax rates for domestic investors and at $20 \%$ for foreign 
investors. Corporate income is taxed at a maximum rate of $25 \%$, while personal income is taxed at a maximum rate of $40 \%$. TWSE differs from other markets mainly in two aspects: high turnover rate and high individual trading. The turnover rate in the TWSE is very high - averaging $184 \%$ annually during our sample period (Note 4$)$. The majority of trades are made by individual investors, which account for over $70 \%$ capitalization. Day trading is also prevalent in Taiwan (Barber et al., 2008), most of which can be traced to individual investors (97.5\%). (Note 5)

\subsection{Sample and Data Description}

The TWSE changed its pre-trade transparency policy in year 2003. Before January 1, 2003, investors in TWSE observed only the price and volume of the best quote. After the change, the price and volume of the five best quotes are opened to market participants. This provides us with a natural experiment. We examine the effect of pre-trade transparency by analyzing data from the two periods. The market of the pre-event period, from July 2002 to December 2002, is opaque, while the market of the post-event period, from January 2003 to June 2003, is transparent. To evaluate the effects of pre-trade transparency, we examine traders' strategies, execution quality, and the execution costs for the two periods.

The sample consists of 508 common stocks listed on the TWSE, which represents almost the entire market (Note 6). Table 1 summarizes the basic descriptive statistics of sample firms during the pre- and post-event period according to three aspects: trading activities, liquidity, and volatility. The average daily trading volumes for the 508 sample firms are 108 and 116 million shares, respectively, in the pre- and post-event period. Trading activities are booming in the market with higher pre-trade transparency. Average trading volume in dollars declines with increasing transparency, which may be caused by the decline in the trading price of stocks between the pre- and post-event period. The effective spread, the distance between the executed price and the prevailing mid-quote price, decreases significantly from 0.41 to 0.38 percent, which implies that liquidity increases in the transparent period. The result shows that market volatility declines after the transparence improvement. The return volatility in the pre- and post-event period, measured by the standard deviation of the daily rate of return, is 2.99 and 2.84, respectively. The daily high-low price difference significantly declines from 0.65 to 0.55 percent (Note 7). From the results of Table 1, we find that trading activities and liquidity are improved and price volatility does not increase after the introduction of a higher pre-trade transparency policy.

Further, we use a complete dataset, which contains detailed order and trade data to investigate intraday trading behavior. Order data is comprised of the time of submission to the nearest second, the order type (buy or sell), price, size, as well as details on change, cancellation records, and the trader's identity for each order. TWSE traders are individuals or institutional traders. Institutional traders include mainly foreign investors, mutual funds, and dealers. Trade data includes the executed time, trade size, and the link to order data for each trade. In a call market, a trade comprises many orders on both sides. Our dataset allows us to track every order that is executed in one trade. By matching the order and trade dataset, we can calculate the filled rate, execution time, and execution costs for each order from individual and institutional traders. For instance, a buy order is submitted by an individual at 10:00 am, the size is 10,000 shares and the price is 10 . We track this order in all trade data for the day and find that 5,000 shares are executed at 10:10 am, and 2,000 shares are executed at 10:20 am. The price of execution is 10 and 9.5, respectively. The filled rate of this order is 70 percent $(=(5,000+2,000) / 10,000)$ and the volume-weighted average of the execution time is 771 seconds $(=(600$ secs $* 5,000$ shares $+1,200$ secs $* 2,000$ shares $) / 7,000$ shares $)$. The execution price of this order is also measured by the volume-weighted average, which is $9.857(=10 * 5,000$ shares $+9.5 * 2,000$ shares $) / 7,000$ shares $)$.

\section{Methodology}

\subsection{Measuring changes of trading strategies}

In the TWSE, a consolidated limit-order book environment, only limit orders are accepted. Traders needing the immediacy trade with "marketable" limit orders, which can be executed in the next call. As defined in Lee et al. (2004), the orders to buy at or above the lowest prevailing ask price, or orders to sell at or below the highest prevailing bid price are deemed marketable, but unexecuted marketable orders are not included in calculations (Note 8). Non-marketable limit orders are orders excluding marketable orders. In this study, marketable limit orders and non-marketable limit orders are separated to explore the trading strategies of different participants. We first analyze adjustments in the trading strategies of institutional and individual investors following the increase of pre-trade transparency. The analysis covers several aspects: number of orders, order sizes, and cancellation of limit orders. All measures are aggregated within a trading day, and the daily average within the pre- and post-event period is calculated. Goettler et al. (2005) argue that because traders monitor the market, they cancel their orders if the consensus value moves in an adverse direction. Having more information due to pre-trade transparency, we expect traders may cancel their orders more frequently. We collected the cancellation records and calculate the daily number of cancellations, the cancellation rate (number of cancellation / number of orders in the day) and the average size of cancellations. 


\subsection{Measuring changes in trading costs}

We measured the effect of pre-trade transparency on trading costs in terms of execution quality and execution costs induced by the submissions. Execution quality includes filled rate and execution time. Execution time is the weighted average of seconds per order waiting for execution. Trading costs include commissions and execution costs. The former remains unchanged in a transparent market, while the latter is paid implicitly through the prices at which trades are completed, and may be influenced by market conditions. According to the literature, execution costs are broadly measured by effective spread. Huang and Stoll (1996), Lee (1993), and Bessembinder and Kaufman (1997) argue that the effective spread is an estimated of the percentage execution cost actually paid by trader and is a gross revenue to the supplier of liquidity. We calculate trading costs of marketable and non-marketable limit orders submitted by institutional and individual traders as follows.

$$
\text { Execution } \operatorname{Cost}_{i, j}=D_{i, j} * \ln \left(p_{i, j} / m_{i, j}\right)
$$

where $D_{i, j}$ equals one for a buy order and minus one for a sell order, and $p_{i, j}$ denotes the volume-weighted average of the execution price for stock i for order j. $m_{i, j}$ denotes the midpoint of the best bid-ask prices immediately prior to the order entering the book (Note 9). Execution cost measures the difference between the real value of the stock and the price paid or received by a trader and thus it is a good proxy of trading cost. We investigate the execution cost by the orders' type (marketable vs. non-marketable limit orders) and the traders' type (institutional vs. individual traders). Marketable limit orders pay costs to demand immediacy, and thus the execution costs of marketable limit orders are expected to be positive. On the other hand, non-marketable limit orders providing liquidity are compensated for price premium, and thus the execution costs are expected to be negative. Anand et al. (2005) find that orders submitted by institutional investors convey more information than individual investors, and thus they are expected to induce a higher price impact or execution cost.

\subsection{Regression analysis}

To isolate the effect of higher pre-trade transparency on traders' costs, we performed a regression analysis, taking into account other factors. Following Griffiths et al. (2000), we include order size, order aggressiveness, and price volatility as the decision variables for the execution cost of an order. Jones and Lipson (1999) measure execution costs and find that execution costs are increasing with order size. Keim and Madhavan (1997) find that technical traders and index traders take on more aggressive strategies when they establish positions, and thus incur higher costs than value traders. Griffiths et al. (2000) and Anand et al. (2005) also find that the more aggressive and larger orders tend to incur higher trading costs because they convey more information. Davydoff et al. (2003) find that trading costs, measured by quote spreads and effective quote spreads, increase the volatility of return. Griffiths et al. (2000) indicate that greater stock price volatility makes traders less willing to supply liquidity since greater losses can arise in holding and adjusting inventory positions. Smith et al. (2001) relate price volatility of stocks to the price impact, suggesting that price volatility is a proxy of information flow, and that higher price volatility implies a greater flow of new information.

We divided samples into four groups based on investor and order types: institutional and marketable limit orders, institutional and non-marketable limit orders, individual and marketable limit orders, and individual non-marketable limit orders. For each firm, we run the following regression analysis separately for four sub-samples with order-level data.

$$
\text { Execution } \text { Cost }_{i, j=} \beta_{0}+\beta_{1} \text { Trans }+\beta_{2} \text { Size }_{i, j}+\beta_{3} \text { Agg }_{i, j}+\beta_{4} \text { Vol }_{i, j}
$$

where Trans denotes transparency dummy. Trans equals one if the sample is from the post-transparency period and zero otherwise. Size represents order size in thousand shares. Agg denotes aggressiveness of orders. In the regression of marketable orders, $A g g$ equals 1 if the price of buy (sell) order is at the best ask (bid) price and equals zero otherwise. In the regression of non-marketable limit orders, $A g g$ equals 3 if the price of an order is between the best bid and the best ask, 2 if the price of a buy (sell) order is at best bid (ask) price and 1 if the price of a buy (sell) order is lower than the best bid (ask) price. Vol is standard deviation of 10 trades immediately prior to the order submission.

\section{Empirical Results}

We first analyzed the changes of trading strategies by traders' type following the enhancement of transparency. We then examined the trading costs measured by execution costs over two sub-periods. Finally, we examined the effects of pre-trade transparency on traders' trading costs by taking into account other factors. 


\subsection{Effects on Trading Strategies}

We investigated the change of trading strategies by observing the number of orders, order sizes, and cancellation record. Results by order type, and trader's identity are summarized in Table 2. From panel A of Table 2, we find the percentage of limit-order trade increased from $42.98 \%$ to $45.76 \%$ for institutional investors, and from $56.17 \%$ to $58.11 \%$ for individual investors after the market became more transparent. The results indicate that both institutional and individual investors are more willing to provide liquidity in an open environment. Additionally, order sizes by different traders are presented in panel B of Table 2. After an increase in transparency, individuals increased the size of marketable limit orders from 7.99 to 8.15 thousand shares (from 124.15 to 123.81 thousand dollars), whereas institutional traders did not significantly raise the size of their marketable orders. On the other hand, individuals increased their non-marketable limit order size from 8.1 to 8.32 thousand shares (from 125.01 to 126.74 thousand dollars), while institutional traders decreased the size of limit orders by 2.35 thousand shares ( 73.08 thousand dollars). These results suggest that individual traders tend to provide liquidity more intensively by submitting more and bigger limit orders, while institutional traders react differently, submitting more and smaller limit orders. In other words, institutional traders split orders into smaller ones in response to increased market transparency.

We also present rates for the cancellation of orders in panel $\mathrm{C}$ of Table 2. The average cancellation rate for institutional traders increases significantly from $26 \%$ to $34 \%$, while the cancellation rate for individual traders significantly decreases from $35 \%$ to $34 \%$. This finding implies that institutional traders attempt to adjust their position more frequently when they can see more information in the limit order book. Our findings indicate that in a more transparent market, both individual and institutional traders seem more willing to provide liquidity but do so using different strategies. Individual traders tend to provide liquidity more intensively by submitting more and bigger limit orders, whereas institutional traders split orders into smaller units and cancel more orders. Traders may face disadvantages because exposed limit orders can be used to construct trading strategies aimed explicitly at taking advantage of their limit orders. Boehmer et al. (2005) argue that investors submit smaller limit orders and cancel orders faster to avoid the disadvantages associated with opening the limit order book. Our results provide evidence of a change in trading strategies. We find that only institutional investors trade strategically in a transparent market to manage the limit-order exposure. In contrast, individual investors become more confident with more information, and submit more and larger limit orders.

\subsection{Effects on Trading Costs}

We measured the change of execution quality and execution costs in two sub-periods. Table 3 reports the average and median for filled rates, volume-weighted execution time, and execution costs for orders placed during the pre-period and post-period, according to trader type. T-tests and the Wilcoxon-test are used to examine the differences. Panel A of Table 3 shows that the execution time of institutional liquidity demanders, who trade with marketable limit orders, decreases significantly from 158 to 135 seconds. This finding implies that institutional traders are able to time the market better when they can see more content in the limit order books. Individual traders' execution time also decreases from 88 to 86 seconds, but this is not significant. Additionally, trading costs for both institutional and institutional traders who demand immediacy, decline after the transparency enhancement. The average execution cost is reduced from 0.0033 to 0.0031 for institutional traders. Individual traders also enjoy a lower execution cost. Therefore, with better execution quality and lower trading costs, liquidity demanders benefit from higher pre-trade transparency.

The results of non-marketable limit orders are presented in panel B of Table 3. Investors who trade with limit orders in an order-driven market provide liquidity. We first compared the filled rate of limit orders and found no significant improvement in the transparent period. As for the execution time, our results demonstrate that institutional traders submit their orders more efficiently when they can see more content in the limit order book. Institutional traders significantly shorten their execution time from 1071.49 to 1033.77 seconds. However, the execution cost for institutional traders' submissions increases significantly by 12.9 percent $(=(-0.0027+0.0031) / 0.0031)$. Why the execution cost of non-marketable limit orders is negative? As mentioned earlier, non-marketable limit order are preferred by traders with low demand for immediacy, but more concerned with transaction costs. This type of order provides liquidity to traders who need immediate execution and will be compensated by execution at a better price. In other word, the negative execution cost can be seen as a compensation for providing liquidity in the market. In an opaque market, non-marketable limit orders have a longer execution time and lower filled rate, but compensate for this by being executed at a better price. After the transparency enhancement, the increasing execution cost indicates the compensation for traders of non-marketable limit orders decreases. On the other hand, individual traders do not benefit from the cut in execution time, whose difference is not significant. In addition, the execution cost for individual traders' submissions increases significantly by 0.024 percent. The results of Table 3 suggest that liquidity demanders benefit from more information acquired from open limit order book, while liquidity providers appear to suffer loss in a more transparent market. Our 
results confirm the argument of Baruch (2005) that opening the limit-order book is beneficial to liquidity demanders.

\subsection{Regression Analysis}

Does pre-trade transparency affect the trading cost of participants in the market? In this section, we examine this issue by taking into account other factors, including order sizes, order aggressiveness and price volatility. We performed a regression analysis on order-level data for each stock and report the average of cross-sectional coefficient of regressions variables in Equation (2). A T-test is used to test the average coefficient across samples. We also report the percentage of positive (negative) coefficients, the percentage of positive (negative), and significant coefficients (Note 10). The results of marketable limit orders are presented in Table 4, while the results of non-marketable limit orders are summarized in Table 5.

According to the results from Table 4, the coefficients of order size and aggressiveness are positive, indicating that larger and more aggressive market orders induce higher trading costs, which is consistent with Griffiths et al. (2000) and Anand et al. (2005). As expected, the coefficients of Vol are positive. In a market with higher price volatility, liquidity demanders' submissions result in higher execution costs due to a greater flow of new information. Furthermore, the coefficients of Trans are significantly negative, which implies that pre-trade transparency reduce the execution costs of liquidity demanders. Both institutional and individual traders, who submit marketable limit orders, trade with lower costs because they can observe more details in the limit order book. In other words, investors who trade for liquidity benefit from the pre-trade transparency enhancement.

On the other hand, pre-trade transparency affects liquidity providers who trade with non-marketable limit orders, differently. As shown in Table 5, the coefficients of Trans are positive, indicating that the execution cost of limit orders increases with market transparency. Liquidity suppliers suffer from higher costs or less compensation for providing liquidity. However, the coefficient is significant only in the regression of individual traders' orders. The result suggests that individual traders suffer from welfare loss, while institutional traders do not. This finding is interesting and can be explained by the difference between individual traders' and institutional traders' trading strategies. Recall the results in Table 2. We find that institutional investors trade strategically by splitting orders and canceling orders faster in a transparent market. Due to their strategic trading, they succeed in managing limit-order exposure, which may cause liquidity suppliers to reveal to the market private information about the value of the security. In contrast, individual traders submit more and larger limit orders, which results in competition. Therefore, they are compensated less for providing liquidity. Our findings are different from those published by Boehmer et al. (2005). In their study, they do not classify limit orders by trader's type. They find that limit-order traders attempt to prevent themselves from limit-order exposure by submitting smaller orders and canceling orders faster. According to our results, we find only institutional traders perform strategic trading to avoid possible loss, while individual liquidity providers suffer the most loss in a more transparent market.

\section{Conclusion}

Market transparency is an important issue in security markets. However, it is still unclear whether or not higher transparency benefits participants in the market and enhances market performance. Findings from empirical studies are mixed. Some studies suggest that disclosing more content in the limit order book can improve market liquidity, and lower price volatility. Whereas findings from other studies do not support these arguments. We discuss this issue from a different point of view, i.e., traders' strategies and trading costs. By using a complete dataset, we investigated how investors change strategies in response to enhanced transparency, and how their trading costs changed when they could see more content in the limit order book.

Our results, measured by the execution cost of their orders, demonstrate that liquidity demanders benefit from the pre-trade transparency by trading at a lower cost. On the other hand, liquidity providers, who trade with non-marketable limit orders, may lose money in an open market. This is because they reveal to the market private information about the value of the security, and exposed limit orders can be used to construct trading strategies aimed explicitly at taking advantage of these limit orders (Harris, 1996). Our findings suggest that individuals face higher trading costs while institutional traders do not. This is because institutional investors, who are generally more sophisticated than individuals, mitigate their loss by splitting orders and canceling orders faster in response to potential disadvantages. Therefore, they do not face significant loss in a transparent market. In contrast, individual liquidity providers trade with more and larger limit orders, thus they suffer the biggest loss after the enhancement of transparency. Pre-trade transparency could enhance market liquidity in general by affecting the trading strategies and trading costs of different participants in the market. 


\section{References}

Anand, A., Chakravarty, S., \& Martell, T. (2005). Empirical evidence on the evolution of liquidity: Choice of market versus limit orders by informed and uninformed traders. Journal of Financial Markets. 8, 289-309. http://dx.doi.org/10.1016/j.finmar.2005.03.001

Barber, B. M., Lee, Y. T., Liu, Y. J., \& Odean, T. (2008). Just how much do individual investors lose by trading? Review of Financial Studies. 22, 609-632. http://dx.doi.org/10.1093/rfs/hhn046

Baruch, S. (2005). Who benefits from an open limit-order book? Journal of Business. 78, 1267-1306.

Boehmer, E., Saar, G., Yu, L., 2005. Lifting the veil: An analysis of pre-trade transparency at the NYSE. Journal of Finance. 60, 783-815. http://www.jstor.org/stable/10.1086/430860

Chung, K. H., Chuwonganant, C. (2009). Transparency and market quality: Evidence from Super Montage. Journal of Financial Intermediation. 18, 93-111. http://dx.doi.org/10.1016/j.jfi.2008.01.002

Davydoff, D., Gajewski, J. F., Gresse, C., \& Grillet-Aubert, L. (2003). Trading cost analysis: a comparison of Euronext Paris and the London Stock Exchange. Working Paper (IEM Finance, Université Paris XII, Université X, 2003).

Flood, M. D., Huisman, R., Koedijk, K. G., \& Mahieu, R.J. (1999). Quote disclosure and price discovery in multiple-dealer financial markets. Review of Financial Studies. 12, http://dx.doi.org/37-59. 10.1093/rfs/12.1.37

Friedman, D. (1993). Privileged traders and asset market efficiency: A laboratory study. Journal of Financial and Quantitative Analysis. 28, 515-534. http://dx.doi.org/10.2307/2331163

Gerke, W., Arneth, S., Bosch, R., \& Syha, C. (1997). Open and closed order book and its effect on liquidity and volatility-market microstructure of stock exchanges in experiments and in the Neuer market. Working paper (Universität Erlangen-Nürnberg).

Goettler, R. L., Parlour, C. A., \& Rajan, U. (2005). Equilibrium in a dynamic limit order market. Journal of Finance. 60, 2149-2192. http://dx.doi.org/10.1111/j.1540-6261.2005.00795.x

Griffiths, M., Smith, B., Turnbull, D., \& White, R. W. (2000). The costs and the determinants of order aggressiveness. Journal of Financial Economics. 56, 65-88. http://dx.doi.org/10.1016/S0304-405X(99)00059-8

Harris, L. (1996). Does a large minimum price variation encourage order exposure? Working paper (University of Southern California)

Harris, L. (1998). Optimal dynamic order submission strategies in some stylized trading problems. Financial Markets, Institutions and Instruments. 7, 1-76. http://dx.doi.org/10.1111/1468-0416.00019

Huang, R. \& Stoll, H. (1996). Dealer versus auction markets: a paired comparison of execution costs on NASDAQ and the NYSE. Journal of Financial Economics. 41, 313-357. http://dx.doi.org/10.1016/0304-405X(95)00867-E

Keim, D. B \& Madhavan, A. (1997). Transactions costs and investment style: An inter-exchange analysis of institutional equity trades. Journal of Financial Economics. 46, 265-292. http://dx.doi.org/10.1016/S0304-405X(97)00031-7

Lee, C. (1993). Market integration and price execution for NYSE-listed securities. Journal of Finance. 48, 1009-1038. http://www.jstor.org/stable/2329024

Lee, Y. T., Liu, Y. J., Roll, R., \& Subrahmanyam, A. (2004). Buy-sell imbalances and market efficiency: evidence from the Taiwan Stock Exchange. Journal of Financial and Quantitative Analysis. 39, 327-341. http://dx.doi.org/10.1017/S0022109000003094

Ma, T., Lin, Y., \& Chen, H. K. (2008). Are investors more aggressive in transparent Markets? Asia-Pacific Journal of Financial Studies. 37, 343-380. http://apjfs.org/data/articles/138.pdf

Madhavan, A. (1996). Security prices and market transparency. Journal of Financial Intermediation. 5, 255-283. http://dx.doi.org/10.1006/jfin.1996.0015

Madhavan, A., Porter, D., \& Weaver, D. (2005). Should securities markets be transparent? Journal of Financial Markets. 8, 265-287. http://dx.doi.org/10.1016/j.finmar.2005.05.001

Pagno, M. \& Röell, A. (1996). Transparency and liquidity: A comparison of auction and dealer markets with informed trading. Journal of Finance. 51, 579-611. http://www.jstor.org/stable/2329372

Smith, B. F., Alasdair, D., Turnbull, S., \& White, R. W. (2001). Upstairs market for principal and agency trades: Analysis of adverse information and price effect. Journal of Finance. 56, 1723-1746. http://www.jstor.org/stable/2697736 


\section{Notes}

Note 1. Friedman (1993) demonstrated that displaying the entire book, as opposed to only the best bid and offer, reduces the market bid/ask spread, but does not significantly vary price information efficiency. Gerke et al. (1997) found lower volatility in the transparent setting but no difference in spreads. Chung and Chuwonganant (2009) examine the effect of pre-trade transparency on market quality using data before and after the introduction of SuperMontage and show both bid-ask spreads and return volatility declined significantly after its implementation.

Note 2. Madhavan et al. (2005) examine the effect of an increase in pre-trade transparency for the Toronto Stock Exchange and found that volatility and execution costs increase while liquidity decreases with increasing transparency.

Note 3. Market orders will be executed immediately, while limit orders will be executed contingent on the price level. Specifically, market orders guarantee certain execution, but uncertain price. Limit orders provide traders with certainty of execution prices, but no guarantee of execution. In an order-driven market, limit orders contingent on the price level will be kept in the limit order book and wait to be executed by incoming market orders. Thus, limit orders provide liquidity while market orders demand liquidity.

Note 4. We calculate turnover as half the sum of buys and sells in each year divided by the average daily market capitalization for that year.

Note 5. Day trading is defined as the purchase and sale of the same stock on the same day by an investor.

Note 6. The sample is filtered through two criteria. First, we delete stocks that did not trade every day during the sample period, keeping 524 stocks in the sample. Second, we delete stocks with per day order numbers of less than 20, keeping 508 stocks in the final sample. The purpose of the filter is to avoid outliers caused by extremely illiquid stocks. All stocks in the sample are listed on the TWSE from July 2002 to June 2003.

Note 7. The high-low price difference is measured as

$$
\frac{\text { highest price of the day - lowest price of the day }}{\text { (highest price of the day }+ \text { lowest price of the day)/2}}
$$

Note 8. Market orders are used by traders who demand the immediacy of execution. In a dealership market, dealers are obliged to execute all orders at the best available price, i.e. best bid and ask price. But in the TWSE, a consolidated limit-order book environment, traders who need to buy (sell) a stock immediately will submit a limit order contingent on the price which is at or above (lower) the best ask (bid) price. Therefore, the limit orders which intend to be executed immediately are regarded as "marketable orders", while those limit orders which wait to be executed in limit order book are regarded as "non-marketable orders". Please refer to Lee et al. (2004) for the detailed procedure of distinguishing marketable and non-marketable limit orders.

Note 9. For example, the best bid and ask price of a stock are 10 and 11. A trader who wants to buy the stock will submit a marketable buy limit order at the price of 11 and this buy order will be executed immediately (in the next call). In the case, D equals $1 ; \mathrm{p}$ is $11 ; \mathrm{m}$ is $10.5(=(10+11) / 2)$; and the execution cost equals 0.0465 . On the other hand, A trader who wants to sell the stock will submit a marketable sell limit order at the price of 10 and this sell order will be executed immediately (in the next call). In the case, $\mathrm{D}$ equals $-1 ; \mathrm{p}$ is $10 ; \mathrm{m}$ is $10.5(=(10+11) / 2)$; and the execution cost equals 0.0488 .

Note 10. The percentage of positive (negative) coefficients is calculated as the numbers of positive (negative) coefficients divided by numbers of sample firms. The percentage of positive (negative) and significant coefficients is calculated as the numbers of positive (negative) and significant coefficients divided by numbers of sample firms. 
Table 1. Descriptive statistics in pre-event and post-event period

PanelA Trading activities

daily trading volume in thousand shares

daily trading volume in thousand dollars

\begin{tabular}{|c|c|c|c|c|c|c|}
\hline & Pre-period & Post-period & Post-Pre & Pre-period & Post-period & Post-Pre \\
\hline Mean & 5028.29 & 5911.03 & $882.75 * * *$ & 122399.81 & 121389.54 & -1010.27 \\
\hline Median & 1854.69 & 2169.67 & $314.98 * * *$ & 28647.51 & 35471.42 & $6823.92 * * *$ \\
\hline Std Dev & 9722.37 & 9829.17 & & 286812.00 & 241712.34 & \\
\hline
\end{tabular}

PanelB Liquidity

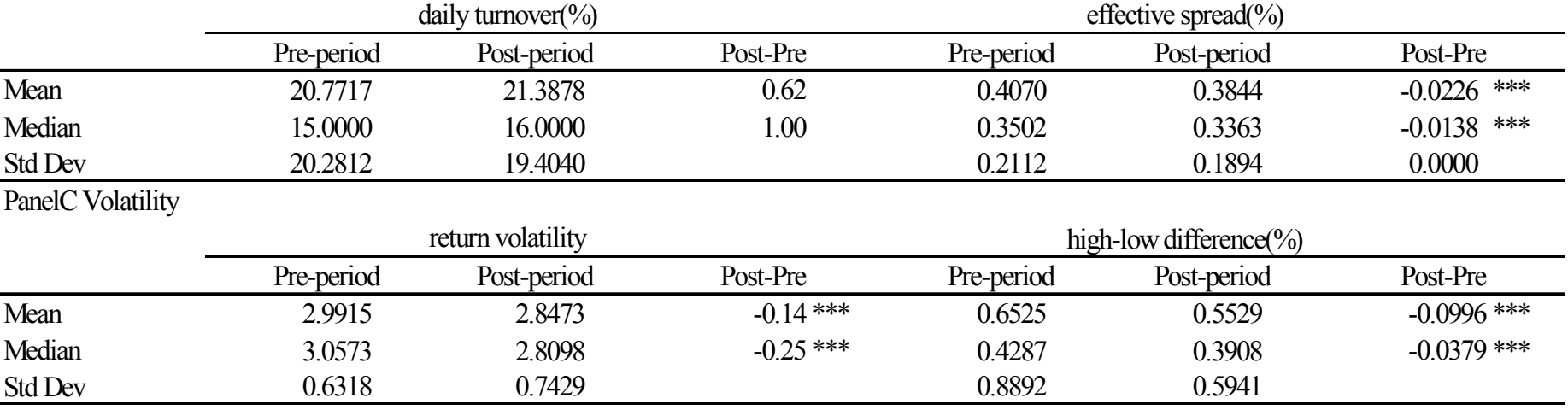

This Table reports descriptive statistics of the sample firms listed on the TWSE. Two periods are used in the study: the pre-event period (less transparent period, July 2002 to December 2002) and post-event period (more transparent period, January 2003 to June 2003). Descriptive statistics are provided for trading activities, liquidity and volatility of sample firms. Measures of trading activities include daily trading volume in thousand shares and in thousand dollars. Liquidity measures include daily turnover and averaging effective spread in percentage terms (the distance between the transaction price and the prevailing midquote scaled by the prevailing midquote). Return volatility is measured as the standard deviation of daily rate of return. High-low difference is measured by averaging the distance of the highest and the lowest price of each trading day. T-tests (Wilcoxon z-tests) is used test the difference of mean (median). ***, ** and * denote significance at the $1 \%, 5 \%$ and $10 \%$ levels respectively.

Table 2. Trading strategies by investor's type in pre-event and post-event period

\begin{tabular}{|c|c|c|c|c|c|c|c|c|c|c|}
\hline \multirow{2}{*}{$\begin{array}{l}\text { Panel A } \\
\text { Number of orders }\end{array}$} & \multicolumn{5}{|c|}{ institutional investors } & \multicolumn{5}{|c|}{ individual investors } \\
\hline & Pre-period & Post-period & Post-Pre & t-statistic & & Pre-period & Post-period & Post-Pre & t-statistic & \\
\hline \multicolumn{11}{|l|}{ Marektable limit order } \\
\hline Number of orders & 62.33 & 76.65 & 14.32 & 5.95 & $* * *$ & 985.33 & 1036.12 & 50.78 & 1.32 & \\
\hline Proportion of orders ( $\%)$ & 57.02 & 54.24 & -2.79 & -4.71 & *** & 43.83 & 41.89 & -1.94 & -10.40 & $* * *$ \\
\hline \multicolumn{11}{|l|}{ Non-marketable limit order } \\
\hline Number of orders & 41.49 & 54.68 & 13.19 & 7.53 & $* * *$ & 1021.37 & 1084.02 & 62.64 & 1.86 & $*$ \\
\hline Proportion of orders ( $\%)$ & 42.98 & 45.76 & 2.79 & 4.71 & $* * *$ & 56.17 & 58.11 & 1.94 & 10.40 & $* * *$ \\
\hline
\end{tabular}

Presented in Table 2 are trading strategies by type of investor (institutional and individual traders) in pre- and post-event periods. The pre-event period ranges from July 2002 to December 2002 and post-event period is January 2003 to June 2003. We observe trading strategies in terms of number of orders, order size and cancellations of orders. Orders to buy at or above the lowest prevailing ask price or orders to sell at or below the highest prevailing bid price are defined as marketable limit orders. We collect the cancellation records and calculate the daily number of cancellation, cancellation rate (number of cancellation / number of orders in the day) and average size of cancellation. T-test is used to test the difference between two periods. $* * *, * *$ and $*$ denote significance at the $1 \%, 5 \%$ and $10 \%$ levels respectively. 
Table 2. (Continued)

\begin{tabular}{|c|c|c|c|c|c|c|c|c|c|c|}
\hline \multirow{2}{*}{$\begin{array}{l}\text { Panel B } \\
\text { Order size } \\
\end{array}$} & \multicolumn{5}{|c|}{ institutional investors } & \multicolumn{5}{|c|}{ individual investors } \\
\hline & Pre-period & Post-period & Post-Pre & t-statistic & & Pre-period & Post-period & Post-Pre & t-statistic & \\
\hline \multicolumn{11}{|l|}{ Marektable limit order } \\
\hline Order size in thousand shares & 29.32 & 28.62 & -0.70 & -1.07 & & 7.99 & 8.15 & 0.16 & 2.76 & $* * *$ \\
\hline Order size in thousand dollars & 551.38 & 501.22 & -50.15 & -3.96 & $* * *$ & 124.15 & 123.81 & -0.34 & -0.25 & \\
\hline \multicolumn{11}{|l|}{ Non-marketable limit order } \\
\hline Order size in thousand shares & 38.59 & 36.24 & -2.35 & -2.08 & $* *$ & 8.10 & 8.32 & 0.21 & 3.34 & $* * *$ \\
\hline Order size in thousand dollars & 687.93 & 614.84 & -73.08 & -3.92 & $* * *$ & 125.01 & 126.74 & 1.73 & 1.28 & \\
\hline Panel C & \multicolumn{5}{|c|}{ institutional investors } & \multicolumn{5}{|c|}{ individual investors } \\
\hline Cancellation & Pre-period & Post-period & Post-Pre & t-statistic & & Pre-period & Post-period & Post-Pre & t-statistic & \\
\hline Number of cancellation & 10.39 & 12.80 & 2.41 & 6.56 & $* * *$ & 216.50 & 214.14 & -2.37 & -0.29 & \\
\hline Cancellation rate & 0.26 & 0.34 & 0.08 & 8.41 & $* * *$ & 0.35 & 0.34 & -0.01 & -1.88 & $*$ \\
\hline Average size of cancellation & 35.86 & 35.66 & -0.20 & -0.19 & & 10.60 & 11.24 & 0.64 & 5.29 & $* * *$ \\
\hline
\end{tabular}

Presented in Table 2 are trading strategies by type of investor (institutional and individual traders) in pre- and post-event periods. The pre-event period ranges from July 2002 to December 2002 and post-event period is January 2003 to June 2003. We observe trading strategies in terms of number of orders, order size and cancellations of orders. Orders to buy at or above the lowest prevailing ask price or orders to sell at or below the highest prevailing bid price are defined as marketable limit orders. We collect the cancellation records and calculate the daily number of cancellation, cancellation rate (number of cancellation / number of orders in the day) and average size of cancellation. T-test is used to test the difference between two periods. $* * * * *$ and $*$ denote significance at the $1 \%, 5 \%$ and $10 \%$ levels respectively.

Table 3. Execution quality and trading cost by investor's type in pre-event and post-event period

\begin{tabular}{|c|c|c|c|c|c|c|c|c|c|c|c|}
\hline \multicolumn{12}{|c|}{ Panel A: Marketable limit order } \\
\hline & & \multicolumn{5}{|c|}{ Institutional investors } & \multicolumn{5}{|c|}{ Individual investors } \\
\hline & & Pre-period & Post-period & Post-Pre & \multicolumn{2}{|c|}{$\begin{array}{l}\text { t-statistic } \\
\text { z-statistic }\end{array}$} & Pre-period & Post-period & Post-Pre & \multicolumn{2}{|l|}{$\begin{array}{l}\text { t-statistic } \\
\text { Z-statistic }\end{array}$} \\
\hline \multirow[t]{2}{*}{ Execution time (seconds) } & ) average & 158.25 & 135.14 & -23.11 & -4.02 & $* * *$ & 87.95 & 86.38 & -1.57 & -1.12 & \\
\hline & median & 123.62 & 106.60 & -17.02 & -5.59 & $* * *$ & 74.81 & 72.29 & -2.52 & -1.65 & * \\
\hline \multirow[t]{2}{*}{ Execution cost } & average & 0.0033 & 0.0031 & -0.0002 & -2.07 & $* *$ & 0.0031 & 0.0030 & -0.0001 & -2.56 & ** \\
\hline & median & 0.0027 & 0.0026 & -0.0001 & -3.24 & $* * *$ & 0.0025 & 0.0025 & 0.0000 & -1.71 & $*$ \\
\hline
\end{tabular}

Presented in Table 3 is the analysis of execution quality in pre-event and post-event period. The pre-event period ranges from July 2002 to December 2002 and post-event period is January 2003 to June 2003. Orders to buy at or above the lowest prevailing ask price or orders to sell at or below the highest prevailing bid price are defined as marketable limit orders. Filled rate is the percentage of a non-marketable limit order executed. Execution time is the volume-weighted average of the execution time. Execution cost is defined as follows:

Execution Cost $_{i, j}=D_{i, j} * \ln \left(p_{i, j} / m_{i, j}\right)$

where $D_{i, j}$ equals one for a buy order and minus one for a sell order, and $p_{i, j}$ denotes the volume-weighted average of the execution price for stock i for order j. $m_{i, j}$ denotes the midpoint of the best bid-ask prices immediately prior to the order entering the book. T-tests (Wilcoxon z-tests) is used test the difference of mean (median). ${ }^{* *},{ }^{* *}$ and $*$ denote significance at the $1 \%, 5 \%$ and $10 \%$ levels respectively. 
Table 3. (Continued)

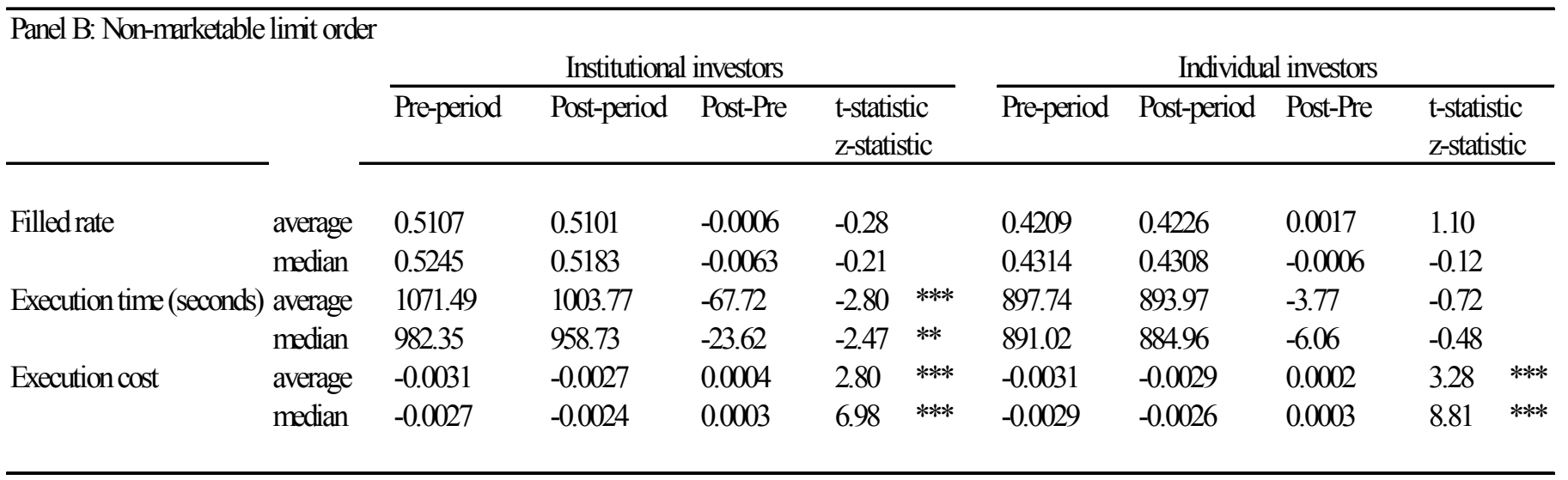

Presented in Table 3 is the analysis of execution quality in pre-event and post-event period. The pre-event period ranges from July 2002 to December 2002 and post-event period is January 2003 to June 2003. Orders to buy at or above the lowest prevailing ask price or orders to sell at or below the highest prevailing bid price are defined as marketable limit orders. Filled rate is the percentage of a non-marketable limit order executed. Execution time is the volume-weighted average of the execution time. Execution cost is defined as follows:

Execution Cost $_{i, j}=D_{i, j} * \ln \left(p_{i, j} / m_{i, j}\right)$

where $D_{i, j}$ equals one for a buy order and minus one for a sell order, and $p_{i, j}$ denotes the volume-weighted average of the execution price for stock i for order $\mathrm{j} . m_{i, j}$ denotes the midpoint of the best bid-ask prices immediately prior to the order entering the book. T-tests (Wilcoxon z-tests) is used test the difference of mean (median). ***, ** and $*$ denote significance at the $1 \%, 5 \%$ and $10 \%$ levels respectively.

Table 4. Regression analysis on marketable limit orders by investor's type

\begin{tabular}{|c|c|c|c|c|c|c|c|c|}
\hline \multirow[b]{2}{*}{ Execution cost } & \multicolumn{4}{|c|}{ Institutional market order } & \multicolumn{4}{|c|}{ Individual market order } \\
\hline & Trans & size & Agg & vol & Trans & size & Agg & vol \\
\hline average & $-0.00024 * *$ & 0.00084 & 0.00188 & $* * * 0.02105 \quad * * *$ & $-0.00019 * * *$ & $0.00024^{* * * *}$ & $0.00085 * * *$ & $0.00321 \quad * *$ \\
\hline positive $(\%)$ & $45.67 \%$ & $91.70 \%$ & $92.73 \%$ & $60.90 \%$ & $40.21 \%$ & $98.69 \%$ & $91.64 \%$ & $54.05 \%$ \\
\hline positive and significant(\%) & $24.22 \%$ & $79.93 \%$ & $84.08 \%$ & $24.57 \%$ & $36.68 \%$ & $99.21 \%$ & $92.08 \%$ & $44.06 \%$ \\
\hline negative $(\%)$ & $54.33 \%$ & $8.30 \%$ & $7.27 \%$ & $39.10 \%$ & $59.37 \%$ & $0.26 \%$ & $7.39 \%$ & $45.38 \%$ \\
\hline negative and significant(\%) & $38.41 \%$ & $1.38 \%$ & $2.08 \%$ & $15.57 \%$ & $55.67 \%$ & $0.26 \%$ & $7.12 \%$ & $38.26 \%$ \\
\hline
\end{tabular}

This table presents the regression results of effects of pre-transparency on execution costs by taking into account other factors, including size, aggressiveness and volatility. The regression model is as: Execution Cost ${ }_{i, j}=\beta_{0}+\beta_{1}$ Trans $+\beta_{2}$ Size $_{i, j}+\beta_{3}$ Agg $_{i, j}+\beta_{4} \operatorname{Vol}_{i, j}$, where "Execution Cost ${ }_{i, j}$ " is defined as Table 3. "Trans" is transparency dummy. "Trans" equals one when sample is from the post-event period and zero otherwise. "Size" represents order size in thousand shares. Agg denotes aggressiveness of orders. Agg equals 1 (more aggressive) if the price of buy (sell) order is at the best ask (bid) price and equals zero otherwise. Vol is standard deviation of 10 trades immediately prior to the order submission. The average (medium) value of regression coefficient across samples is provided, and t-test is used to determine whether the average value of regression coefficient across samples is significant. *** denote significance at the $1 \%$ level. The third (fifth) row of this table, namely, positive (negative) and significant (\%), is calculated based on 5\% significant level. 
Table 5. Regression analysis on non-marketable limit orders by investor's type

\begin{tabular}{|c|c|c|c|c|c|c|c|c|c|c|c|}
\hline \multirow[b]{2}{*}{ Executioncost } & \multicolumn{4}{|c|}{ Institutional limit order } & \multicolumn{7}{|c|}{ Individual limit order } \\
\hline & Trans & size & Agg & $\mathrm{vol}$ & Trans & & size & & Agg & & vol \\
\hline average & 0.00008 & 0.00001 & $0.00175 * * *$ & -0.01198 *** & 0.00014 & *wok & 0.00007 & $* * *$ & 0.00113 & * * w & -0.00350 \\
\hline positive $(\%)$ & $61.73 \%$ & $69.75 \%$ & $96.91 \%$ & $39.92 \%$ & $61.15 \%$ & & $93.46 \%$ & & $98.16 \%$ & & $34.76 \%$ \\
\hline positive and significant $(\%)$ & $3251 \%$ & $3251 \%$ & $90.12 \%$ & $10.91 \%$ & $48.88 \%$ & & $84.25 \%$ & & $97.55 \%$ & & $25.77 \%$ \\
\hline negative $(\%)$ & $38.27 \%$ & $30.25 \%$ & $3.09 \%$ & $60.08 \%$ & $38.85 \%$ & & $6.54 \%$ & & $1.84 \%$ & & $65.24 \%$ \\
\hline negative and significant $(\%)$ & $13.58 \%$ & $6.38 \%$ & $0.62 \%$ & $24.69 \%$ & $30.88 \%$ & & $3.48 \%$ & & $1.43 \%$ & & $55.42 \%$ \\
\hline
\end{tabular}

This table presents the regression results of effects of pre-transparency on execution costs by taking into account other factors, including size, aggressiveness and volatility. The regression model is as: Execution Cost ${ }_{i, j}=\beta_{0}+\beta_{1}$ Trans $+\beta_{2}$ Size $_{i, j}+\beta_{3}$ Agg $_{i, j}+\beta_{4} \operatorname{Vol}_{i, j}$, where "Execution Cost E $_{i, j}$ " is defined as Table 3. "Trans" is transparency dummy. "Trans" equals one when sample is from the post-event period and zero otherwise. The pre-event period ranges from July 2002 to December 2002 and post-event period is from January 2003 to June 2003. "Size" represents order size in thousand shares. Agg denotes aggressiveness of orders. Agg equals 3 if the price of an order is between the best bid and the best ask (most aggressive), 2 if the price of a buy (sell) order is at best bid (ask) price and 1 if the price of a buy (sell) order is lower than the best bid (ask) price. $\mathrm{Vol}$ is standard deviation of 10 trades immediately prior to the order submission. The average (medium) value of regression coefficient across samples is provided, and t-test is used to determine whether the average value of regression coefficient across samples is significant. $* * *$ denote significance at the $1 \%$ level. The third (fifth) row of this table, namely, positive (negative) and significant (\%), is calculated based on 5\% significant level. 